\title{
Publisher Correction: Dietary shifts can reduce premature deaths related to particulate matter pollution in China
}

Xueying Liu (D), Amos P. K. Tai (D), Youfan Chen (D), Lin Zhang (D), Gavin Shaddick, Xiaoyu Yan (D) and Hon-Ming Lam (D)

Correction to: Nature Food https://doi.org/10.1038/s43016-021-00430-6, published online 16 December 2021.

In the version of this article initially published, there was an error in Fig. 1b. The label originally reading "Vegetables" has been corrected to read "Meat." The change has been made to the HTML and PDF versions of the article.

Published online: 7 January 2022

https://doi.org/10.1038/s43016-022-00458-2

(C) The Author(s), under exclusive licence to Springer Nature Limited 2022 